Western University

Scholarship@Western

Centre for Human Capital and Productivity. CHCP

Working Papers

Economics Working Papers Archive

2011

2011-06 An International Comparison of Lifetime Inequality: How Continental Europe Resembles North America

Audra J. Bowlus

University of Western Ontario, abowlus@uwo.ca

Jean-Marc Robin

Follow this and additional works at: https://ir.lib.uwo.ca/economicscibc

Part of the Economics Commons

Citation of this paper:

Bowlus, Audra J., and Jean-Marc Robin. "An International Comparison of Lifetime Inequality: How Continental Europe Resembles North America." CIBC Centre for Human Capital and Productivity. CIBC Working Papers, 2011-6. London, ON: Department of Economics, University of Western Ontario (2011). 


\title{
An International Comparison of Lifetime Inequality: How Continental Europe Resembles North America
}

$$
\text { by }
$$

Audra J. Bowlus and Jean-Marc Robin

Working Paper \# 2011-6

August 2011

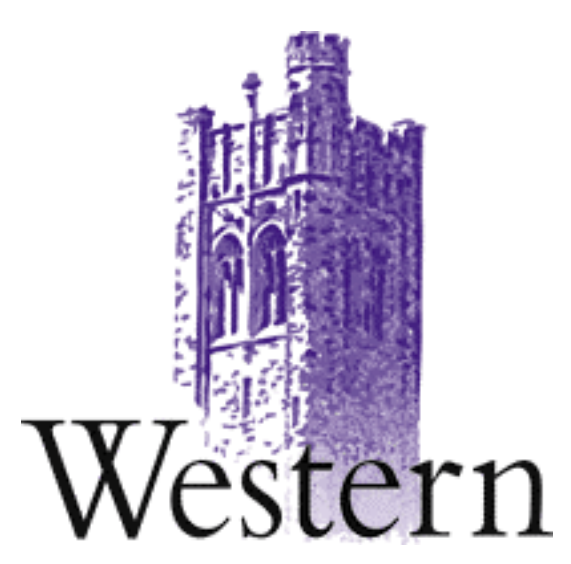

\section{CIBC Working Paper Series}

\author{
Department of Economics \\ Social Science Centre \\ The University of Western Ontario \\ London, Ontario, N6A 5C2 \\ Canada
}

This working paper is available as a downloadable pdf file on our website http://economics.uwo.ca/centres/cibc/ 


\title{
An International Comparison of Lifetime Inequality: How Continental Europe Resembles North America
}

\author{
Audra J. Bowlus \\ University of Western Ontario
}

\author{
Jean-Marc Robin \\ Sciences Po, Paris, \\ and University College London
}

February 22, 2011

\begin{abstract}
We compare earnings inequality and mobility across the U.S., Canada, France, Germany and the U.K. during the late 1990s. A flexible model of earnings dynamics that isolates positional mobility within a stable earnings distribution is estimated. Earnings trajectories are then simulated, and lifetime annuity value distributions are constructed. Earnings mobility and employment risk are found to be positively correlated with base-year inequality. Taken together they produce more equalization in countries with high cross-section inequality such that the countries in our sample have more similar lifetime inequality levels than crosssection measures suggest.
\end{abstract}

\section{Acknowledgements:}

We thank the editor, three anonymous referees, Joseph Altonji, Richard Blundell, Martin Browning, Peter Gottschalk, Steven Haider, Robert Moffitt, Giuseppe Moscarini, Bernard Salanié, and Gary Solon for helpful comments and discussion. We also thank participants in seminars at University of Oxford, New York University, Columbia University, Yale University, and the Institute for Fiscal Studies, and conference sessions at the First Annual CLSRN conference, the second annual UM/MSU/UWO Labor Economics Day, and the Canadian Econometrics Study Group. Audra J. Bowlus gratefully acknowledges financial support from the Social Science and Humanities Research Council and data assistance at the University of Western Ontario's Research Data Centre. Jean-Marc Robin gratefully acknowledges the financial support from the Economic and Social Research Council for the ESRC Centre for Microdata Methods and Practice, "Cemmap" (grant reference RES-589-28-0001), and from the Direction de l'Animation de la Recherche, des Etudes et des Statistiques (DARES) of the French Ministère de l'Emploi et de la Solidarité (convention no. 4028).

E-mail addresses: Bowlus: abowlus@uwo.ca; Robin: jeanmarc.robin@sciencespo.fr 


\section{Introduction}

Because individuals are subject to shocks that change and exchange their positions within earnings distributions, cross-sectional survey data offers an incomplete picture of earnings inequality across countries or different groups within the same country. In order to account for such sources of instability as employment risk and earnings mobility, it is essential to consider long-run measures of earnings inequality. Earnings mobility that occurs within a stable earnings distribution is an equalizing force across individuals and thus leads to lower lifetime inequality. Hence, a comparison of long-run inequality measures to current or base-year inequality measures reveals the degree of equalization mobility in each country. If countries with high levels of current inequality exhibit a large amount of equalization mobility, then cross-country comparisons of current inequality overstate long-run differences. If the opposite is true, any long-run differences are understated.

In this paper we study cross-country differences in current and lifetime earnings inequality for the U.S., Canada, the U.K., France and Germany. These countries showcase both a range of earnings inequality levels and a range of earnings mobility and employment risk patterns leading to differences in lifetime inequality levels. Differences in institutions and labour market policies across these countries have been linked to differences in current inequality (e.g. minimum wage policies). The same differences can also result in mobility differences and, subsequently, differences in lifetime inequality. The OECD Employment Outlook 2004 provides a precise description of cross-country differences in employment protection regulation and wage-setting institutions, and their effects on labour market performance. It finds that stricter employment protection legislation is associated with lower unemployment inflow and outflow rates. It also shows that our chosen countries exhibit significant variation in the strictness of their employment protection legislation with the U.S., the U.K. and Canada at the bottom of the index and France and Germany near the top.

Here we do not attempt to model institutional differences across the countries nor the behavioural responses of individuals to them. Instead we take as 
given that these differences are part of what generates the observed differences in earnings and mobility patterns across these countries, and develop a statistical framework that replicates these patterns. We then use the estimates from the statistical model to generate lifetime earnings distributions, and examine whether these differences also lead to differences in lifetime inequality.

As discussed in MaCurdy (2007), there are two sources of variation in earnings data: (1) macroeconomic dynamics that govern changes in the cross-sectional distribution over time, and (2) microeconomic dynamics that govern individuals' relative positions within a stable cross-sectional distribution over consecutive periods. The first type of mobility, labeled structural mobility by MaCurdy, is related to changes in the earnings distribution due to business cycle fluctuations or growth. The second type of mobility concerns movements within a stable distribution, and is labelled by MaCurdy as positional mobility. Since structural mobility differs across countries, it is important to isolate positional mobility when assessing the degree of equalization across countries.

Long-run earnings inequality studies are usually based on measures of permanent income obtained by averaging observed earnings series. This has the drawback of mixing structural and positional mobility. An alternative is to specify a dynamic earnings model that explicitly models both sources of mobility. For example, complex factor models with time-varying factor loadings are used such that different earnings components have different calendar-time dynamics. ${ }^{1}$ Both of these approaches require lengthy panel data sets. Since only a few countries have collected long panel data sets, the number of cross-country studies of earnings mobility and long-run earnings inequality is small relative to the large literature comparing cross-section earnings inequality across countries. ${ }^{2}$ Our idea

\footnotetext{
${ }^{1}$ See MaCurdy (2007) for a survey, and the particular examples of Moffitt and Gottschalk (1995, 2002), Baker (1997), Haider (2001), Baker and Solon (2003), Geweke and Keane (2000, 2007), Meghir and Pistaferri (2004), Browning et al. (2009), Altonji et al. (2007) and Pavan (2008).

${ }^{2}$ Examples of comparative studies of mobility include the following. Aaberge et al. (2002) compare the U.S. and Scandinavian countries. Burkhauser, Holtz-Eakin and Rhody (1997),
} 
is to use sufficiently short panels so as to mitigate the problem of structural mobility and have the advantage of bringing more countries into the comparison.

Thus the goal of this paper is to develop a model of earnings dynamics that uses short panels for estimation to reduce, if not eliminate, structural change; that is flexible enough to fully capture positional earnings mobility and employment risk; and that allows for the simulation of lifetime earnings and thus the calculation of equalization mobility across countries. Because the panels are short our model does not capture unobserved heterogeneity fully. Our response is to provide estimates from two models - one that overestimates positional mobility by neglecting unobserved heterogeneity and one that underestimates position mobility by allowing for individual fixed effects. ${ }^{3}$ The actual amount of equalization mobility for each country is then in between the two measures.

Our model incorporates the main feature of dynamic earnings models in that it has the familiar factor structure with a deterministic component, a permanent component, and a transitory, covariance-stationary component. It differs, however, on three dimensions. First, the permanent component is a standard fixed effect. Thus, it allows for very little unobserved heterogeneity compared to Browning et al. (2009), Altonji et al. (2007) and Pavan (2008). Second, the transitory component is only first-order Markov and much simpler than, for example, the ARCH process in Meghir and Pistaferri (2004). However, because we model the transitory component in a very flexible way, we do not impose any undue symmetry on the transition process. Thus our model is closer to the more traditional Burkhauser and Poupore (1997), Maasoumi and Trede (2001), and Schluter and Trede (2003) compare the U.S. and Germany. Van Kerm (2004) compares Belgium, Western-Germany and the U.S. Buchinsky et al. (2003), Fields (2009), Cohen (1999) and Cohen and Dupas (2000) study France and the U.S. Italy and the U.S. are compared by Flinn (2002). For cross-country comparisons of earnings inequality see the surveys of Levy and Murnane(1992), Katz and Autor (1999) and Gottschalk and Smeeding (2000).

\footnotetext{
${ }^{3}$ The OLS estimator of the autoregressive coefficient of an $\operatorname{AR}(1)$ panel data model is upward biased (positive correlation between the regressor and the error) and the Within-Group estimator is biased toward zero (as in a measurement error problem).
} 
earnings mobility literature (e.g. Gottschalk 1997; Buchinsky and Hunt 1999). Finally, we explicitly model employment risk rather than excluding unemployed individuals or treating unemployment income as part of the earnings distribution.

Our main results are as follows. First, our model captures the data well, including transitions in the tails of the earnings distributions. Second, the U.S. displays the most positional earnings mobility with the U.K. second followed by Canada, Germany and France. Third, the U.S. also displays more employment mobility followed closely by the U.K. and Canada. France and Germany display far less employment mobility than the other countries. Fourth, lifetime inequality measures that incorporate only positional earnings mobility result in the same cross-country inequality rankings with the U.S. displaying the most inequality. Fifth, the inclusion of employment risk brings the countries closer together because it is an equalizing factor in the U.S., the U.K. and Canada and a non-equalizing factor in France and Germany. Thus, despite large differences in earnings inequality in 1998, overall the countries display more similar lifetime inequality levels.

Our use of simulation methods to construct lifetime earnings profiles to estimate long-run inequality is related to Flinn (2002), Bowlus and Robin (2004) and Bonhomme and Robin (2008), Cohen (1999), and Cohen and Dupas (2000). Flinn (2002), Bowlus and Robin (2004) and Cohen (1999) use search frameworks to model earnings dynamics. In contrast, our model is considerably more flexible because it is not restricted by the stringent implications of search theory and it allows for unobserved heterogeneity. Bonhomme and Robin (2008) also move away from search theory and use parametric copulas to model earnings dynamics. They show that the parametric choice of the copula matters for the decomposition of the variance of earnings into permanent and transitory components. This finding motivates our adoption of a semiparametric model for the dynamics of earnings ranks. In addition, Bonhomme and Robin (2008) use a random-effect approach to unobserved heterogeneity. This renders inference difficult. ${ }^{4}$ For this

\footnotetext{
${ }^{4}$ The extreme nonlinearity of the mixture model makes the estimation numerically tricky. Bonhomme and Robin (2008) use a sequential EM algorithm in a pseudo-maximum likelihood estimation approach. However, Flinn (2002) reports that he tried to introduce a random effect
} 
paper, we estimate a fixed effect for each individual, which is much simpler but requires more data for consistency. Finally, Bowlus and Robin (2004) and Bonhomme and Robin (2008) study the dynamics of inequality and mobility in a single country, while Flinn (2002), Cohen (1999) and Cohen and Dupas (2000) compare two countries. One contribution of this paper is to conduct an international comparison of long-run earnings inequality across more countries, thus offering a more comprehensive picture of the effect of labour market institutions on long-run inequality.

The plan of the paper is as follows. The next section develops a theoretical framework for computing lifetime earnings. The data and the fit of the model are discussed in Section 3. Section 4 analyzes the results and conclusions are given in Section 5.

\section{The Model}

\subsection{Earnings Distribution Specification}

To isolate the dynamics of individual positions within marginal earnings distributions separately from the dynamics of the marginal distributions themselves we remove any structural variation by regressing log earnings on time dummies interacted with education dummies with 1998 as the control year. It is fairly standard to use time dummies to control for structural mobility (see MaCurdy 2007). We did experiment with time effects interacted with experience groups and time effects in the variance function as well as the mean function, but found that we were able to remove the macroeconomic effects with time dummies interacted with education and in the mean function only. The short nature of the panel data renders a more sophisticated time-series process unnecessary. We then treat the filtered data as if all remaining dynamics reflect only positional mobility.

Let $w_{h t}$ denote the earnings with the time effects removed for an employed in his model but his ML estimator failed to converge. 
worker $h$ at time $t$. Next, we posit a linear regression for log earnings

$$
\ln w_{h t}=x_{h t} \beta+f_{h}+e_{h t},
$$

where $x_{h t}$ is a vector of regressors comprising education dummies interacted fully with a quartic function of potential experience. ${ }^{5}$ We allow (or not, for comparison) for an individual fixed effect $f_{h}$. Here we follow a Mincerian earnings regression approach by including only education and experience as explanatory variables. ${ }^{6}$ This is a standard approach for the earnings equation in the mobility literature (see Altonji et al. 2007; Buchinsky and Hunt 1999; Pavan 2008). Altonji et al. and Pavan are also able to include employer tenure in their earnings regressions. Unfortunately not all of our data sets collect information on tenure. Thus we are not able to include this human capital component.

In the version of the model without fixed effects we estimate the model using OLS. The fixed effect model is estimated using a fixed effect regression model where time invariant regressors such as education are subsumed into the fixed effect. We also allow for conditional heteroskedasticity of the following form

$$
\operatorname{Var}\left(e_{h t} \mid x_{h t}\right)=x_{h t} \gamma
$$

where the parameter vector $\gamma$ is estimated by regressing the squared residuals $\widehat{e}_{h t}^{2}$ on $x_{h t}$. To improve efficiency, we then re-estimate $\beta$ and $f_{h}$ by weighted least squares, with weights proportional to $\left(x_{h t} \widehat{\gamma}\right)^{-1 / 2}$ (feasible GLS procedure).

\footnotetext{
${ }^{5}$ Note that we cannot allow $\beta$ to depend on time as $\beta$ is a parameter in the model used to simulate long term earnings trajectories.

${ }^{6}$ Gender is also included by estimating the model separately for males and females. Race is not included because it is not available in all of the data sets, but is controlled for in the fixed effect model.
} 


\subsection{Transitions}

Standard ARIMA models of earnings dynamics typically require only a few parameters and, therefore, characterize changes in earnings means and variances well but fail to produce a good description of mobility in the tails of the distributions (tail dependence). For example, earnings decreases (increases) should be more likely when one is at the top (bottom) of the earnings distribution rather than movements up and down being equally likely regardless of placement in the distribution. Thus, it is thus important to allow for non-symmetric dynamics. We adopt the common practice of examining matrices of transition probabilities across deciles (e.g. Buchinsky and Hunt 1999).

Let $G$ be the cumulative distribution function (cdf) of the standardized residuals, $u_{h t}=e_{h t} / \sqrt{x_{h t} \gamma}$. We estimate $G$ by the empirical cdf of $\widehat{u}_{h t}=\widehat{e}_{h t} / \sqrt{x_{h t} \widehat{\gamma}}$. Let $r_{h t}=G\left(u_{h t}\right)$ be the rank of the residual $u_{h t}$ in the distribution $G$. We estimate $r_{h t}$ by $\widehat{r}_{h t}=\widehat{G}\left(\widehat{u}_{h t}\right)$. Finally, let $q_{h t}$ denote a discrete version of the ranks $r_{h t}$,

$$
q_{h t}=\max \left\{\frac{\left\lfloor N r_{h t}\right\rfloor+1}{N}, 1\right\}
$$

where $\lfloor\cdot\rfloor$ is the integer part function. Note that $q_{h t}$ is never equal to 0 . Hence, we use the notation $q_{h t}=0$, if individual $h$ is unemployed at time $t$. We call the "state" the value of $q_{h t}$ in $\{0,1 / N, 2 / N, \ldots, 1\}$. In the empirical analysis $N$ is set equal to 10 .

Incorporating transitions between employment and unemployment is nonstandard in the earnings dynamics literature. However, employment risk has been shown to be an important component of variation in earnings and lifetime inequality (see Bowlus and Robin 2004; Altonji et al. 2007; Pavan 2007). In addition the wide variation in employment risk across countries makes a difference in cross-country comparisons. Thus, we include unemployment as a state in our transition matrix in order to incorporate employment risk in our analysis.

Because of small sample sizes for some of our countries we parameterize the transition matrix rather than clustering the data and non-parametrically estimating the transition probabilities. The latter leads to partitioning the data too 
finely and zero probability events. Thus one would be left with large clusters to avoid this problem. Let $P\left(i, j \mid x_{h t}\right)$ be the probability of moving from state $q_{h t}=i$ at time $t$ to state $q_{h, t+1}=j$ at time $t+1$, with $\sum_{j} P\left(i, j \mid x_{h t}\right)=1$. We parameterize the transition probabilities $P\left(i, j \mid x_{h t}\right)$ using multinomial logits for each initial state $i^{7}$ Specifically,

$$
P\left(i, j \mid x_{h t}\right)=\frac{\exp \left[x_{h t} \kappa(i, j)\right]}{\sum_{m=0}^{N} \exp \left[x_{h t} \kappa(i, m)\right]} .
$$

The set of covariates includes an experience quadratic and the education dummies. We would prefer to include more explanatory variables as well as interactions between the variables. However, small sample sizes within these clusters prevent the estimation of a full set of transition probabilities.

Even with a limited set of covariates some destination cell sizes are too small, e.g. destination quantiles distant from the quantile interval of origin. Here we collapse infrequent destination quantiles together. Specifically, upper and lower destination deciles are combined by collapsing all destination deciles $[(j-1) / 10, j / 10]$ such that $|j-i|>k$, for some $k$, where $[(i-1) / 10, i / 10]$ is the decile of origin. In the empirical analysis only the U.S. has a large enough sample size and mobility levels such that the full 11 by 11 transition matrix can be recovered using the multinomial logit specification. For Canada, the U.K. and Germany, $k$ was set equal to 3 , while for France a less restrictive formulation was able to be used such that $k=4 .^{8}$

\footnotetext{
${ }^{7}$ The multinomial logit specification is restrictive only insofar as it assumes a single index model for the effect of covariates $x_{h t}$ on each transition probability. The recourse to linear indices is the only practical way of dealing with the curse of dimensionality in nonparametric estimation.

${ }^{8}$ We did conduct an experiment on the U.S. data of setting $k=4$. We found the lifetime inequality measures were slightly smaller when the cells were collapsed, because the rank placement method is now responsible for placement within the collapsed deciles rather than the multinomial logit models. Consequently, individuals are less likely to end up in the actual destination decile if it is at the top or bottom of the distribution.
} 
Having produced an approximation of the joint distribution of ranks at times $t$ and $t+1$ given covariates $x_{h t}$ at discrete nodes, we then obtain an approximation over the whole range of rank values by using a nearest neighbor procedure (i.e. the matching estimator of the treatment effect literature). Given $r_{h t}$ and $x_{h t}$ we predict the quantile at $t+1, q_{h, t+1}$, using the multinomial logit models. Then we predict $r_{h, t+1}$ as the value of $r_{h, t+1}$ in the data that yields the closest match of $r_{h t}$ and $q_{h, t+1}$. In this way we do not impose the common assumption in the literature of random placement within deciles and instead preserve the within decile transition patterns. In the Appendix we provide a comparison of the fit of the earnings dynamics using two alternative strategies: random assignment within the destination decile and rank assignment within the destination decile. The latter refers to an individual maintaining the rank he held in the initial decile in the destination decile. Our chosen nearest neighbor method has the best overall fit of the within decile earnings dynamics compared to the two alternatives. In particular, it does a good job of fitting the dynamics in the tails of the earnings distribution.

One aspect of the earnings data we do not model is measurement error. In general validation studies of wage and earnings data find that measurement error is nonclassical and mean reverting (Bound et al. (2001) and Gottschalk and Huynh (2007)). While classical measurement error overstates inequality, nonclassical measurement error understates inequality. In terms of earnings mobility the effect of nonclassical measurement error is less clear. Evidence from Gottschalk and Huynh using data from the U.S. Survey of Income and Program Participation (SIPP) matched to U.S. tax records (assumed to be measured without error) indicates that the effects of nonclassical measurement error are largely offsetting when examining earnings mobility. That is, estimates of the correlation in earnings over time from the SIPP are found to be similar to estimates from the tax records. Since we do not have access to validation data for each country nor an identification strategy for estimating the form and/or degree of measurement error, we do not attempt to incorporate measurement error into our model. We recognize that our measures of earnings inequality may understate the true levels, 
but we expect the reporting biases to be similar across the countries and we are encouraged by Gottschalk and Huynh's finding that our mobility measures may not be biased.

\subsection{Simulation of the Value Functions}

Bowlus and Robin (2004) computed both ex ante and ex post lifetime income values with the former based on taking expectations or averaging over expected future transition paths and the latter based on a single simulated path for each individual in the sample. Here we adopt the ex post measure of lifetime income values as our unit of analysis, but in the Appendix we provide the results for the ex ante measure. The cross-country comparison results are the same for the two measures. Averaging simulated paths to compute the ex ante values, as expected, produces lower levels of lifetime inequality than the ex post measure. This is particularly true for the model without the fixed effect. The model with the fixed effect produces virtually identical ex ante and ex post lifetime inequality levels. This is because the fixed effects already contain the average component that is captured in the ex ante measure.

To simulate an individual's remaining path from some date $t$ onward we start with the current (observed) employment state and salary. Next, we randomly draw a sequence of states for the periods following $t$ until retirement based on potential experience and other personal characteristics using the same marginal distribution $G$ and transition probability matrix $P$. So doing, we allow the individual's age to change and modify the earnings process but the macroeconomic environment responsible for shifts in $G$ and $P$ is held fixed in its state at time $t$.

While employed, individuals receive the annualized value of their earnings. Since we also include employment risk, we need to determine unemployment income. Here we incorporate some cross-country differences in the unemployment insurance systems but certainly not to the fullest extent possible given data limitations. We allow for income to change over an unemployment spell to capture the fact that unemployment insurance replacement rates decline with the duration of unemployment. To capture cross-country variation in generosity during 
unemployment we also allow the replacement rate levels to vary. Thus income during unemployment is equal to a country-specific replacement rate $\rho$ times the previous period's annual earnings if the individual was working in the previous period and times a minimum earnings level, $\underline{w}$, if the individual was unemployed in the previous period. Because our income measure is gross earnings, we use gross unemployment insurance replacement rates. The rates come from Martin (1996) and were computed by the OECD in 1995 for an individual with a spouse at work. We use the values for the first year of unemployment which are: $25 \%$ for the U.S., $18 \%$ for the U.K., $54 \%$ for Canada, $58 \%$ for France and $35 \%$ for Germany.

Finally, we set income following retirement at age $\bar{a}$ equal to 0 . We do not model differences in social security systems. Instead we take the stance that, if retirement income is paid out of earnings through taxes or self-financing, then retirement income is 0 under an actuarially fair system.

Let $\mathcal{E}_{a t}(w)$ be the discounted sum of the predicted future income stream for someone with age $a$ and earnings $w$ at time $t$. To compare present values across all individuals, not only those within the same cohort, we compute the annuity value of employment rather than the stock value. To convert stock values $\mathcal{E}_{a}(w)$ into annuity values we use the standard formula for an annuity $\mathcal{A}_{a t}(w)$ with interest rate $r$ such that:

$$
\mathcal{A}_{a t}(w)=\frac{\mathcal{E}_{a t}(w)}{\sum_{t=1}^{\bar{a}-a+1} \frac{1}{(1+r)^{t}}}=r \mathcal{E}_{a t}(w) \frac{(1+r)^{\bar{a}-a+1}}{(1+r)^{\bar{a}-a+1}-1} .
$$

In the empirical analysis $r$ is set equal to an annual rate of $5 \%$.

\section{$3 \quad$ Data and Model Fit}

\subsection{Data Description}

In this section we provide a brief overview of the data. A full description of the data sets is in the Appendix. We examine data from the U.S., the U.K., France, Germany and Canada. The inequality analysis below examines the year 1998 with all of the countries having at least three-year panel data sets that 
cover the late 1990's. For the U.S. we use the four-year wave of the SIPP from 1996-1999. For France we use the three-year panel from the French Labor Force Survey (LFS) for 1997-1999. The six-year 1996-2001 wave of the Survey of Labour and Income Dynamics (SLID) is used for Canada. Finally, we use The British Household Panel Survey (BHPS) for the U.K. and the German Socio-Economic Panel (GSOEP) for Germany. For these latter countries we use seven years of data from $1995-2001 .^{9}$

We chose these data sets to make the samples as consistent across the countries as possible. Three of the five data sets are part of the Cross-National Equivalent File (CNEF) - BHPS, GSOEP and SLID. France does not have a data set in the CNEF, but the French LFS has a similar structure to the other panels. The US does have a data set in the CNEF, the Panel Study of Income Dynamics (PSID). We chose the SIPP over the PSID, because the PSID is biennial in the late 1990's and the SIPP's sample size is more than 4 times larger.

For every year an individual is in each panel we collect information on the labour market state at the time of the survey, earnings if employed, education, potential experience, and gender. We impose minimal restrictions to remove those individuals who not active in the labour market, self-employed or in the military. Because of outliers due to erroneous earnings observations, all of the data sets need to be trimmed. We trim earnings at the top and bottom for each sex*education group such that mean earnings reflect each group's relative position in the market. Rather than imposing fixed minimum and maximum levels for each education group, we determine the upper (lower) trim level needed in each country that produced maximum (minimum) and mean values that increased with education, reduced the large amount of kurtosis in the data, and implied plausible maximum (minimum) hourly wages. A upper trim level of $1 \%$ was sufficient for all countries except Canada which needed $2 \%$. A lower trim of only

\footnotetext{
${ }^{9}$ The sample sizes of the BHPS and GSOEP are quite small. To increase the sample size and reveal the full transition matrix we use a longer time period. However, we do not use the full available panels for the U.K. and Germany to make the results more comparable with the other countries and to reduce the movement away from stationarity as additional years are added.
} 
a $1 \%$ was needed for France and Germany. However, a 2\% lower trim level was needed for the U.S., the U.K. and Canada. Even though the levels vary across the countries, our inequality measure is relatively indifferent to the length of the upper and lower tails and thus the results are insensitive to variation in the trim levels around these values.

Our samples are constructed to be similar across the countries with a few exceptions to capture institutional differences. For example, our sample is restricted to individuals between the ages of 16 and 65 for the U.S., U.K. and Canada and ages 16 to 60 for France and Germany with the latter reflecting an earlier retirement age in those countries. Another difference is in the education categories reflecting the different structures of the educational systems and the different responses collected in the data sets. For the U.S., Canada and France there are four education categories that correspond to less than high school, high school, some college, and university. For the U.K. the categories are less than high school, high school graduate and more than high school, while for Germany the categories are based on a years of education measure grouped as follows: no more than 10 years, more than 10 but less than 14 years, 14 or more years.

\subsection{Stationarity of the Earnings Distribution}

In Table 1 we present the stationary equilibrium distributions that stem from our predicted transition probabilities. ${ }^{10}$ If our methodology isolates only positional mobility, the earnings decile elements within each column should be the same and equal to 1 minus the predicted unemployment rate divided by 10 . By construction in the data the elements are the same and equal to 1 minus the actual unemployment rate divided by 10. For most countries and for both men and women, the equilibrium distributions obtained from the homogeneous model

\footnotetext{
${ }^{10}$ To compute equilibrium distributions, we first average the transition probability matrix $P$ across individual characteristics. The equilibrium distribution is then the eigenvector associated with the first eigenvalue of the transpose of $P$. In the cases where the destination deciles are collapsed, we divide the predicted probabilities for entering the combined destination evenly across the deciles contained in that destination state.
} 
show a somewhat uneven spread across the deciles. In the U.S. there is only a slight accumulation in the middle deciles. However, in the U.K. and Canada there is a marked accumulation in the top deciles; in France in the bottom deciles; and in Germany in both tails. Allowing for fixed effects results in a marked improvement for the U.K., Canada and Germany. In the case of France, allowing for fixed effects now induces an accumulation in the middle deciles. Likely three years are not enough for a precise estimation of the fixed effects. Overall the results suggest that our method for removing the structural changes is successful.

Table 1 also shows the predicted stationary unemployment rate as well as the actual unemployment rate in the data used for the transition analysis. Since we use multiple periods to estimate the transition matrix, we mitigate the problem of cyclical variation in unemployment rates to some extent. Because our model matches the average unemployment rate over several years, it is not unduly influenced by any one year. This is important when conducting cross-country comparisons as not all countries may be at the same stage of the business cycle during the base-year. While the results in Table 1 show the model does well at capturing the relative magnitudes of the unemployment rates across the countries, there is a general tendency for the predicted unemployment rates to be lower than the actual unemployment rates. The exception to this finding is France. Closer inspection of the unemployment rates in the data by year shows that for all of the countries, except France, the male and female unemployment rates fall over the sample period. Thus, the inflow (outflow) rates are decreasing (increasing) over time. Since the predicted rates are calculated from these flow rates, this leads to estimated stationary rates that are lower than the actual rates. This effect is more pronounced for those countries with the largest decline in the unemployment rate: males in the U.K. and males and females in Germany and Canada. These are also the countries where we use more years of data and thus can expect to face more challenges related to stationarity. 


\subsection{Cross-Section Distribution of Earnings}

In terms of fit, the proposed regression framework does a good job of capturing the features of the earnings data. Table 2 shows the actual and predicted moments of the earnings distributions for each country for males and females for the specifications without and with unobserved heterogeneity. The model produces a good fit for the mean and standard deviation. The skewness and kurtosis predictions are not quite as good but in most cases the fit is reasonable given that these moments are not functions of the explanatory variables. While both model specifications match the mean and variance, the fixed effect model fits the skewness and kurtosis levels better.

\subsection{Transitions}

In order to examine the performance of our earnings dynamics specification, we compute Spearman's rank correlation using pairs of years from the actual and predicted log earnings data for each country. Spearman's rank correlation is calculated by using ranks instead of levels as in the more common Pearson's correlation calculation. We examine rank rather than level correlations because we are interested in movements within the distribution, not level changes. Further, in the simulation exercise the marginal distribution is fixed and mobility results entirely from rank dynamics. Using the multinomial logit model samples, we compute two rank correlations. ${ }^{11}$ The first one captures the rank correlation in the observed data by computing the correlation between the ranks of actual log earnings in adjacent periods. The second one captures the predicted rank correlations from the model by computing the correlation between ranks for actual log earnings in the first period and the ranks for predicted log earnings from our model in the second period. We examine the rank correlations of the earnings

\footnotetext{
${ }^{11}$ Because we examine rank correlations in the earnings data only respondents who are working in both periods enter into the calculations for the actual correlations, and only respondents who are working in the first period and predicted to be working in the latter period enter into the calculations for the predicted correlations.
} 
data rather than the residuals even though our mobility model is estimated only on the residuals. Thus a comparison of the actual and predicted rank correlations effectively captures how well the full model reproduces the observed earnings mobility.

Table 3 presents the rank correlations conditional on the earnings decile in the first period. To calculate these correlations we start by dividing the first period earnings data into deciles and within each decline assign ranks. Next, we assign ranks to the second period earnings data associated with the first period earnings in each decile. The second period earnings may or may not fall in the same decile. Finally, we compute the Spearman's correlation between the two ranks for each first period decile. We do this calculation twice: once using the actual second period earnings and once using the predicted second period earnings. By subdividing the earnings data in this way we are better able to determine the performance of the model in different parts of the distribution rather than just overall. Both specifications produce a good fit to the data in the middle deciles; for most countries the specification with unobserved heterogeneity produces a slightly better fit in the extreme deciles.

Several features of the data stand out in this table: 1) the U.S. exhibits much lower correlations than any of the other countries, 2) the correlations are larger at the extreme deciles of the distributions than in the middle, 3 ) the correlations are larger for the top than the bottom, and 4) the correlations for males and females within each country are quite similar. The second and third conclusions are important as they justify our more flexible approach to earnings dynamics. In particular, a single correlation parameter does not permit a full characterization of the earnings autocorrelations throughout the entire distribution.

\subsection{Long-run Dynamics}

Given the flexibility of our model specification, it is not surprising that the model can return the main features of the estimation samples. For a model of lifetime earnings the true test is long-run dynamics. To measure the performance of our model over a longer period we compute Spearman's rank correlation using 
the ranks at all possible orders. That is, for each 2-year, 3-year, 4-year, etc. pair observed in the data we compute the rank correlations between the actual earnings levels in the two years and the rank correlation between the actual earnings in the initial year and the earnings level predicted 2, 3, and 4 years later, respectively. Table 4 displays the Spearman rank correlations at all possible orders for each country.

The model with no fixed effect fails to fit the long-run dynamics predicting too much mobility over time resulting in correlations that decrease much faster than those in the data. For example, in the U.S. the correlation in the data falls from 0.76 for 1 -year differences to 0.66 for 3 -year differences, while the model predicts a much lower correlation of 0.49 for 3 -year differences. This pattern is found for both males and females in all of the countries. In comparison the fixed effect model does a much better job, although it predicts more persistence in earnings over time than there is in the data. In fact the fixed effect specification produces very little decrease in the correlation suggesting that the fixed effects essentially maintain individuals' ranks within the distribution. Given these two specifications produce results that encompass the observed correlations, the amount of equalization mobility in each country lies between them.

The figures in Table 4 support the previous finding that the U.S. exhibits more positional mobility than the other countries with no other country coming close to its low correlations. The U.K. exhibits the second highest mobility levels, while Canada and Germany appear, perhaps surprisingly, to be quite similar. Finally, France is the most immobile country with the highest 1-year correlations and no apparent drop in 2-year correlations. Interestingly males and females exhibit the same correlation patterns despite differences in the earnings distributions themselves.

The full sample correlations in Table 4 are higher than the conditional correlations in Table 3. In the limit, if individuals remained in the same decile for ever, the Spearman rank correlation across deciles would be close to one. However, one could still have a very low correlation within deciles. This is not what we find. This is reassuring as it indicates there is nothing special about using deciles. If 
we used a finer discretization, the result would likely be the same.

\section{Lifetime Inequality}

Having demonstrated that our empirical specification provides a good fit of the observed data, we now turn to the calculation of lifetime inequality. Since we do not have income values while unemployed for our base sample, we use only those employed in the base-year in our calculations of current and lifetime inequality. In this way we have comparable samples across all of our calculations.

\subsection{Gender, Education and Experience Effects}

To see how lifetime annuity values differ from earnings Table 5 presents ratios of average earnings and values for education and experience groups by gender. The gender ratio is the female average divided by the male average. The education ratio is the average of the highest education group divided by the average of the lowest. Likewise the experience ratio is the average of those with $25+$ years of experience divided by the average of those with less than 15 years of experience.

Focusing first on gender, we find the gender ratio is substantially less than one in all countries. This is due to the inclusion of part-time workers which are predominantly women. The gender ratio is also similar across the two measures indicating mobility does not alleviate nor exacerbate gender differences. With regard to education and experience, the education premiums increase when comparing earnings ratios to lifetime annuity value ratios. In contrast, the experience premiums decrease. Thus mobility reinforces education differences and eliminates differences across experience groups. The latter is because low experience levels incorporate future growth in earnings in the lifetime annuity value, while higher experience levels incorporate flat to declining future earnings profiles. In terms of inequality, these findings indicate that educational differences tend to enhance long-run inequality, while differences in experience levels tend to reduce it. 


\subsection{Equalization Mobility}

We now turn our attention to a comparison of current and lifetime earnings inequality. Table 6 shows inequality levels for base-year earnings (1998) and lifetime annuity values using $90-10$ ratios for males and females in each country. ${ }^{12}$ The top panel shows the results for the model with no unobserved heterogeneity, while the bottom panel shows the results for the fixed effect model. Within each panel row 1 contains the 90/10 ratios for base-year earnings, while row 6 contains the 90/10 ratios for our calculated lifetime annuity values using the full model including both earnings mobility and employment risk (labeled full mobility). ${ }^{13}$ Following Fields (2009) the amount of equalization mobility is measured by the ratio of the lifetime inequality measure to the base-year inequality measure and is given in row 8 . In between rows 1 and 6 , these panels display counterfactual exercises analyzed below.

Starting with earnings inequality and comparing across countries (row 1), we find that for males the U.S. exhibits the highest level of base-year earnings inequality. Canada and the U.K. exhibit similar levels that are between the U.S. and France and Germany where the latter have the lowest levels. For females, the U.S. has again the highest level. However, the U.K. is now closer to the U.S.; Canada remains in the middle; and France and Germany remain at the bottom.

Turning to lifetime annuity values (row 6), the levels of lifetime inequality are in general lower than the level of earnings inequality. As expected the U.S.

\footnotetext{
${ }^{12}$ Results using other inequality measures such as the Gini coefficient are similar and available upon request.

${ }^{13}$ To compute these calculations we use the 1998 sample only. Because the sample sizes for a single year are relatively small for the U.K., Germany and France, the inequality measures can vary across simulations. Thus we implement the following Monte Carlo: after $n$ iterations of the counterfactual simulations let $x(n)$ be the mean of the $n$ statistics of interest (e.g. 90/10 ratio); stop if $|x(n)-x(n-1)|$ is less than $1 \%$ of $x(n-1)$. The standard deviation of these means for the full mobility specifications are in row 7 . We note that females exhibit more variation than males and Germany with the smallest sample size exhibits the most variation.
} 
exhibits the largest differential between current and lifetime inequality levels (row 8). After the U.S. is Canada and then the U.K. Germany and France have the lowest levels of equalization. Comparing the models with and without fixed effects, the amount of equalization is much smaller in the fixed effect model. Instead of a reduction of inequality of about $30 \%-40 \%$, in the case of the U.S., Canada and the U.K., the reduction is only $10 \%-15 \%$ in the fixed effect model.

\subsection{Counterfactual Analyses}

To determine the relative importance of different forms of mobility we simulate the lifetime annuity values under various scenarios.

\subsubsection{Earnings Mobility Only}

We first isolate the effects of positional earnings mobility by excluding transitions across employment and unemployment. ${ }^{14}$ We examine the level of long-run inequality that results if we allow for only upward earnings mobility, only downward earnings mobility and both. ${ }^{15}$ As expected, positional mobility has an equalizing effect. Interestingly upward earnings mobility results in more equalization than downward earnings mobility except for French males in the homogeneous model. This result underscores the need for a flexible transition model that does not impose symmetry restrictions on up and down movements within the earnings distribution.

While including positional earnings mobility always results in less inequality, the amount varies by country. In general the U.S., Canada and the U.K. see larger reductions than France or Germany. For men, however, the larger reductions for the former countries do not change the fact that they still have higher inequality levels than the latter countries. For women several reversals occur. In the homo-

\footnotetext{
${ }^{14}$ Here we set the probability of exiting to unemployment to zero and transfer that probability to remaining in the current state.
}

${ }^{15}$ For the case of only upward (downward) mobility we set the probability of transiting to lower (higher) deciles to zero and transfer that probability to remaining in the current state. 
geneous model the U.K. now exhibits the highest level of inequality, followed by Germany and then the U.S. In the fixed effect model Germany remains the lowest reversing with France, while the U.S. and the U.K. exchange orderings. Thus, the countries in our study become more similar once positional earnings mobility is taken into consideration.

\title{
4.3.2 Employment Risk Only
}

The inclusion of employment risk only, however, shows a different pattern. When we allow for mobility only between employment and unemployment, ${ }^{16}$ we find the equalization effect is much lower and in some cases employment risk increases inequality in the long-run. ${ }^{17}$ This is especially true for countries such as France and Germany that have a very low exit rate out of unemployment. ${ }^{18}$ Thus, in the long-run, earnings mobility is equalizing, but employment risk is not. This explains why France and Germany exhibit such a limited long-run reduction of inequality. Clearly ignoring employment risk would result in the incorrect conclusion that France and Germany had equalization rates similar to the other countries and therefore substantially lower levels of lifetime inequality.

\footnotetext{
${ }^{16}$ Here we set the probability of changing earnings deciles to zero and transfer that probability to remaining in the current decile.
}

\begin{abstract}
${ }^{17}$ The income received during unemployment is not included in the earnings regression used to calculate the residuals used in the positional earnings mobility process estimation. Since the income assigned to unemployment is a fraction of earnings, the lowest values lie outside the lower bound of the earnings distribution. Thus the inclusion of employment risk adds income values that lower the lifetime annuity values, on average, and in particular those at the low end of the earnings distribution where the risk of unemployment is high. This can result in a higher lifetime inequality levels than the base-year level within our chosen sample of employed workers. If the full sample (employed and unemployed workers) is used, then lifetime inequality is lower than base-year inequality in all countries, but the reduction is still much smaller in France and Germany such that equalization across countries remains.
\end{abstract}

\footnotetext{
${ }^{18}$ For example, the exit rate out of unemployment is 0.27 for France compared to 0.75 for the U.S.
} 
The finding that employment risk is an important component of lifetime inequality is supported by Altonji et al. (2007) and Pavan (2008) who find links between employment risk and earnings. Our full mobility results are also in agreement with studies that use search models to incorporate employment risk and earnings mobility through job changes such as Flinn (2002) and Cohen (1999). In particular, the homogeneous version of our model produces the result that lifetime inequality levels are similar across the countries despite different base-year inequality levels. The similarity in the findings is likely related to the search studies incorporating employment risk but not unobserved heterogeneity.

\subsection{Sensitivity Analysis}

Because the employment risk calculations rely on our assumptions regarding unemployment income, we conduct sensitivity analysis with regard to these assumptions. Table 7 displays the results of counterfactual simulations under three different scenarios and compares them to our original (base) model. In the first case we replace the first-year gross replacement rate with a five-year average of the gross rates in each country and no longer lower unemployment income after the first year. ${ }^{19}$ The five-year averages are lower than the first-year rate because they take into account that countries reduce the replacement rate over time. The reduction is smaller for European countries due to longer durations of unemployment insurance. The five-year averages also take into account the variation in rates across demographic groups as the rates are weighted by the population in each group when taking the average. In the second case we use a five-year average of net replacement rates. In our base model we use the gross replacement rate because we use gross earnings as our income measure. Net replacement rates can be substantially higher than gross replacement rates because they take into account other forms of subsidies to unemployed workers. Net replacement rates

\footnotetext{
${ }^{19}$ All of the rates for this sensitivity analysis are taken from Martin (1996). The 5-year average gross (net) rates are 12\% (16\%) for the U.S., 18\% (51\%) for the U.K., $27 \%$ (43\%) for Canada, $38 \%(55 \%)$ for France and $26 \%$ (54\%) for Germany.
} 
also vary more across demographic groups than gross rates and so these averages reflect those differences as well. The third case assumes the replacement income level during unemployment is 0 .

Table 7 shows that in countries such as the U.S., the U.K. and Canada where employment risk is minimal the results are basically unchanged. However, for France and Germany the lifetime inequality levels change quite a bit across the different cases. For these countries using five-year average rates, especially average net replacement rates, lowers the amount of lifetime inequality in France and Germany for both males and females, while setting unemployment income to 0 increases lifetime inequality substantially. The former result stems from longer unemployment durations in France and Germany and the fact that in the average specifications we do not lower unemployment income over time. The latter result also stems from the fact that unemployment durations are longer in continental Europe, but now with a 0 value for unemployment income lifetime income values are lowered substantially by long unemployment spells. This in turn increases inequality by lowering values at the bottom of the distribution.

As an additional sensitivity test of our results we also used a utility based approach to see if risk aversion made a difference. Using a CRRA utility function specification with an intertemporal substitution elasticity of 2 , Table 8 shows that in general the base-year inequality levels for the utility based approach are much lower than those for the income based approach. The reduction in inequality due to moving to lifetime measures is also smaller. All of the other orderings and conclusions remain the same. The lack of a qualitative effect of introducing risk aversion is likely because we did not model its effect on consumption and savings with incomplete asset markets. Modeling lifetime consumption inequality has been attempted (see Cutler and Katz 1992; Attanasio and Davis 1996; Blundell and Preston 1998; Attanasio et al. 2002) but is severely limited by the lack of consumer panels. 


\section{Conclusions}

In this paper we compare earnings inequality and mobility across the U.S., Canada, France, Germany and the U.K. at the turn of the 21st century. We are interested in the degree to which positional earnings mobility and employment risk in each country reduces lifetime inequality compared to base-year earnings inequality. For positional mobility we construct and estimate a flexible model of individual earnings dynamics for each country that removes structural mobility in order to isolate mobility within a stable earnings distribution. We then simulate individual employment and earnings trajectories given base-year earnings (1998) and construct lifetime annuity value distributions for each country. The ratio of lifetime inequality to base-year inequality is our measure of equalization mobility which we compare across the countries.

To facilitate cross-country comparisons we designed our model to be estimated on panels of relatively short lengths. Despite its simplicity and limited data requirements our model provides a good fit to the earnings and mobility data. Therefore, we conclude short panel data do not forbid measuring the equalizing force of mobility. What it important is the ability to simulate ex post realizations of income over a longer period than that observed in the data.

In our analysis we compare two different models: one which does not allow for unobserved heterogeneity and a simple fixed effect model. The homogeneous model predicts too much mobility over time, while the fixed effect model predicts too little mobility. However, the fit of higher-order rank autocorrelations is much better for the latter model. Thus, two models as deliver upper and lower benchmarks for the measurement of the degree of equalization.

Given our results, we speculate that mobility reduced earnings inequality over a lifetime by about $20 \%-30 \%$ in the U.S., Canada and the U.K. and very little, if at all, in France and Germany in the late 1990s. Within our sample of countries, the countries with relatively higher earnings inequality also have more equalizing mobility. Thus, incorporating mobility reveals that countries with North American-style labour markets are more similar to countries with Continental European-style labour markets in terms of long-run inequality than measures of 
short-run inequality would suggest. This result can be understood within the context of search-matching models. In these models higher employment protection and firing costs lengthen employment spells but also tend to reduce job creation, as firms are wary of expanding if they cannot accommodate negative productivity shocks. Fewer vacancies relative to total search intensity in turn weakens between-firm competition for workers, which reduces offer arrival rates, employment and earnings mobility, and earnings dispersion.

Whether mobility is good or bad is a matter of interpretation. On the one hand, more earnings and employment mobility moves individual positions more in the U.S. than elsewhere, so that the U.S. is not such an unequal country after all. On the other hand, income uncertainty should be negatively valued by risk-averse individuals. Our attempt to introduce risk aversion did not change the results. However, our welfare computations in the presence of risk aversion are not satisfactory, because insurance markets are likely incomplete. More income risk probably means more credit constraints highlighting the limits of the present exercise. A more satisfactory welfare computation allowing for liquidity constraints would require consumption data. The few available studies on consumer welfare seem to indicate there is less consumption inequality than income inequality, and possibly fewer cross-country differences. Given the similarity of our findings to the consumption literature, we think our study goes a long way toward an assessment of cross-country welfare differences.

\section{References}

Aaberge, Rolf, Anders Bjørklund, Markus Jäntti, Mårten Palme, Peder J. Pedersen, Nina Smith, and Tom Wennemo (2002). "Income Inequality and Income Mobility in the Scandinavian Countries Compared to the United States." Review of Income and Wealth, 48, 443-469.

Altonji, Joseph G., Anthony Smith, and Ivan Vidangos (2007). "Modeling Earnings Dynamics." NBER Working Paper No. 14743.

Attanasio, Orazio, and Steven J. Davis (1996). "Relative Wage Movements and 
the Distribution of Consumption." Journal of Political Economy, 104, 1227-1262.

Attanasio, Orazio, Gabriella Berloffa, Richard Blundell, and Ian Preston (2002). "From Earnings Inequality to Consumption Inequality." The Economic Journal, 112(478), C52-C59.

Baker, Michael (1997). "Growth-Rate Heterogeneity and the Covariate Structure of Life-Cycle Earnings." Journal of Labor Economics, 15, 338-375.

Baker, Michael, and Gary Solon (2003). "Earnings Dynamics and Inequality among Canadian Men, 1976-1992: Evidence from Longitudinal Records.” Journal of Labor Economics, 21, 289-321.

Blundell, Richard, and Ian Preston (1998). "Consumption Inequality and Income Uncertainty." Quarterly Journal of Economics, 113(2), 603-640.

Bonhomme, Stéphane, and Jean-Marc Robin (2009). "Assessing the Equalizing Force of Mobility Using Short Panels: France, 1990-2000." The Review of Economic Studies, 76(1), 63-92.

Bound, John, Charles Brown, and Nancy Mathiowetz (2001). "Measurement Error in Survey Data." In Handbook of Econometrics, Vol. 5, edited by James J. Heckman, and Edward E. Leamer. Elsevier.

Bowlus, Audra J., and Jean-Marc Robin (2004). "Twenty Years of Rising Inequality in U.S. Lifetime Labor Income Values." Review of Economic Studies, 71, 709-743.

Browning, Martin, Mette Ejrnæs, and Javier Alvarez (2009). "Modelling Income Processes with Lots of Heterogeneity." Review of Economic Studies, 76, 1-33.

Buchinsky, Moshe, and Jennifer Hunt (1999). "Wage Mobility in the United States." Review of Economics and Statistics, 81, 351-368.

Burdett, Kenneth, and Dale T. Mortensen (1998). "Wage Differentials, Employer Size, and Unemployment." International Economic Review, 39, 257-273. 
Burkhauser, Richard V., Douglas Holtz-Eakin, and Stephen E. Rhody (1997). "Labor Earnings Mobility and Inequality in the United States and Germany during the Growth Years of the 1980s." International Economic Review, 38, 775-794. Burkhauser, Richard V., and John G. Poupore (1997). "A Cross-National Comparison of Permanent Inequality in the United States and Germany." The Review of Economics and Statistics, 79(1), 10-17.

Cohen, Daniel (1999). "Welfare Differentials Across French and U.S. Labor Markets: A General Equilibrium Interpretation." CEPREMAP Working Paper No. 9904 .

Cohen, Daniel, and Pascaline Dupas (2000). "Trajectoires comparées des chômeurs en France et aux Etats Unis." Economie et Statistique, 332, 17-26.

Cutler, David M., and Lawrence F. Katz (1992). "Rising Inequality? Changes in the Distribution of Income and Consumption in the 1980's." American Economic Review 82(3), 546-551.

Fields, Gary S. (2009). "Does Income Mobility Equalize Longer-Term Incomes? New Measures of an Old concept." Journal of Economic Inequality, forthcoming. Flinn, Christopher J. (2002). "Labour Market Structure and Inequality: A Comparison of Italy and the U.S." Review of Economic Studies, 69, 611-645.

Geweke, John, and Michael Keane (2000). "An Empirical Analysis of Income Dynamics among Men in the PSID: 1968-1989." Journal of Econometrics, 96, $293-356$.

Geweke, John, and Michael Keane (2007). "Smoothly Mixing Regressions." Journal of Econometrics, 138, 252-290.

Gottschalk, Peter (1997). "Inequality, Income Growth, and Mobility: The Basic Facts." The Journal of Economic Perspectives, 11(2), 21-40.

Gottschalk, Peter, and Minh Huynh (2010). "Are Earnings Inequality and Mobility Overstated? The Impact of Non-Classical Measurement Error." Review of Economics and Statistics, 92, 302-315. 
Gottschalk, Peter, and Timothy M. Smeeding (2000). "Empirical Evidence on Income Inequality in Industrial Countries." In Handbook of Income Distribution, Vol. 1, edited by Anthony B. Atkinson, and François Bourguignon. Elsevier.

Haider, Steven J. (2001). "Earnings Instability and Earnings Inequality of Males in the United States: 1967-1991." Journal of Labor Economics 19: 799-836.

Katz, Lawrence F., and David H. Autor (1999). "Changes in the Wage Structure and Earnings Inequality." In Handbook of Labor Economics, Vol. 3, edited by Orley C. Ashenfelter, and David Card. Elsevier.

Levy, Frank, and Richard J. Murnane (1992). "U.S. Earnings Levels and Earnings Inequality: A Review of Recent Trends and Proposed Explanations." Journal of Economic Literature, 30, 1333-1381.

Maasoumi, Esfandiar, and Mark Trede (2001). "Comparing Income Mobility in Germany and the United States using Generalized Entropy Mobility Measures." The Review of Economics and Statistics, 83, 551-559.

Martin, John P. (1996). "Measures of Replacement Rates for the Purpose of International Comparison A Note." OECD Economic Studies, 26, 99-115.

MaCurdy, Thomas (2007). "A Practitioner's Approach to Estimating Intertemporal Relationships using Longitudinal Data: Lessons from Applications in Wage Dynamics." In Handbook of Econometrics, Vol. 6, edited by James J. Heckman, and Edward E. Leamer. Elsevier.

Meghir, Costas, and Luigi Pistaferri (2004). "Income Variance Dynamics and Heterogeneity." Econometrica, 72, 1-32.

Moffitt, Robert, and Peter Gottschalk (1995). "Trends in the Covariance Structure of Earnings in the U.S.: 1969-1987." Mimeo, John Hopkins University.

Moffitt, Robert, and Peter Gottschalk (2002). "Trends in the Transitory Variance of Earnings in the U.S." The Economic Journal, 112, C68-C73.

OECD (2004). OECD Employment Outlook 2004. OECD Publishing. 
Pavan, Ronni (2008). "A Flexible Model of Individual Wage Dynamics and Job Mobility Outcomes. " Mimeo, University of Rochester.

Schluter, Christian, and Mark Trede (2003). "Local versus Global Assessment of Mobility." International Economic Review, 44, 1313-1335.

Van Kerm, Philippe (2004). "What Lies Behind Income Mobility? Reranking and Distributional Change in Belgium, Western Germany and the U.S.A.” Economica, $71(282), 223-239$. 


\begin{tabular}{|c|c|c|c|c|c|c|c|c|c|c|}
\hline & \multicolumn{5}{|c|}{ MALES } & \multicolumn{5}{|c|}{ FEMALES } \\
\hline & U.S. & Can. & U.K. & Fra. & Ger. & U.S. & Can. & U.K. & Fra. & Ger. \\
\hline & \multicolumn{10}{|c|}{ Homogeneous Model } \\
\hline \multicolumn{11}{|c|}{ UNEMPLOYMENT } \\
\hline Predicted & 0.023 & 0.051 & 0.045 & 0.139 & 0.078 & 0.020 & 0.047 & 0.025 & 0.161 & 0.098 \\
\hline Actual & 0.033 & 0.072 & 0.069 & 0.137 & 0.094 & 0.031 & 0.077 & 0.037 & 0.169 & 0.140 \\
\hline \multicolumn{11}{|c|}{ EARNINGS DECILES } \\
\hline 1 & 0.089 & 0.085 & 0.097 & 0.117 & 0.119 & 0.081 & 0.076 & 0.056 & 0.104 & 0.097 \\
\hline 2 & 0.098 & 0.097 & 0.096 & 0.117 & 0.094 & 0.093 & 0.082 & 0.065 & 0.103 & 0.089 \\
\hline 3 & 0.102 & 0.087 & 0.088 & 0.107 & 0.080 & 0.099 & 0.078 & 0.073 & 0.101 & 0.075 \\
\hline 4 & 0.100 & 0.081 & 0.081 & 0.097 & 0.074 & 0.102 & 0.083 & 0.076 & 0.088 & 0.075 \\
\hline 5 & 0.100 & 0.082 & 0.080 & 0.088 & 0.070 & 0.102 & 0.087 & 0.077 & 0.094 & 0.068 \\
\hline 6 & 0.100 & 0.080 & 0.082 & 0.077 & 0.072 & 0.102 & 0.088 & 0.090 & 0.086 & 0.073 \\
\hline 7 & 0.098 & 0.085 & 0.088 & 0.066 & 0.075 & 0.103 & 0.093 & 0.102 & 0.079 & 0.072 \\
\hline 8 & 0.098 & 0.096 & 0.101 & 0.066 & 0.091 & 0.099 & 0.107 & 0.121 & 0.070 & 0.089 \\
\hline 9 & 0.098 & 0.114 & 0.112 & 0.063 & 0.106 & 0.100 & 0.120 & 0.144 & 0.059 & 0.11 \\
\hline 10 & 0.091 & 0.143 & 0.130 & 0.065 & 0.141 & 0.098 & 0.140 & 0.172 & 0.056 & 0.152 \\
\hline Actual & 0.097 & 0.093 & 0.093 & 0.086 & 0.091 & 0.097 & 0.092 & 0.096 & 0.083 & 0.086 \\
\hline \multicolumn{11}{|c|}{ Fixed Effect Model } \\
\hline \multicolumn{11}{|c|}{ UNEMPLOYMENT } \\
\hline Predicted & 0.024 & 0.055 & 0.045 & 0.142 & 0.071 & 0.021 & 0.052 & 0.027 & 0.171 & 0.102 \\
\hline Actual & 0.033 & 0.072 & 0.069 & 0.137 & 0.094 & 0.031 & 0.077 & 0.037 & 0.169 & 0.140 \\
\hline \multicolumn{11}{|c|}{ EARNINGS DECILES } \\
\hline 1 & 0.086 & 0.085 & 0.087 & 0.066 & 0.085 & 0.084 & 0.075 & 0.078 & 0.066 & 0.085 \\
\hline 2 & 0.093 & 0.094 & 0.090 & 0.078 & 0.085 & 0.096 & 0.096 & 0.086 & 0.081 & 0.085 \\
\hline 3 & 0.101 & 0.097 & 0.083 & 0.104 & 0.087 & 0.101 & 0.097 & 0.094 & 0.093 & 0.077 \\
\hline 4 & 0.101 & 0.104 & 0.101 & 0.106 & 0.102 & 0.104 & 0.111 & 0.103 & 0.107 & 0.092 \\
\hline 5 & 0.095 & 0.109 & 0.103 & 0.100 & 0.100 & 0.100 & 0.106 & 0.109 & 0.103 & 0.094 \\
\hline 6 & 0.110 & 0.110 & 0.105 & 0.110 & 0.095 & 0.104 & 0.117 & 0.113 & 0.099 & 0.105 \\
\hline 7 & 0.102 & 0.091 & 0.098 & 0.100 & 0.091 & 0.105 & 0.091 & 0.100 & 0.093 & 0.094 \\
\hline 8 & 0.103 & 0.081 & 0.094 & 0.070 & 0.090 & 0.101 & 0.081 & 0.095 & 0.070 & 0.087 \\
\hline 9 & 0.097 & 0.084 & 0.094 & 0.067 & 0.098 & 0.099 & 0.084 & 0.097 & 0.061 & 0.088 \\
\hline 10 & 0.089 & 0.090 & 0.089 & 0.058 & 0.094 & 0.087 & 0.088 & 0.098 & 0.056 & 0.090 \\
\hline Actual & 0.097 & 0.092 & 0.093 & 0.086 & 0.091 & 0.097 & 0.092 & 0.096 & 0.083 & 0.086 \\
\hline
\end{tabular}

Table 1: Comparisons of Predicted Stationary Distributions of Unemployment and Earnings to Actual Distributions 


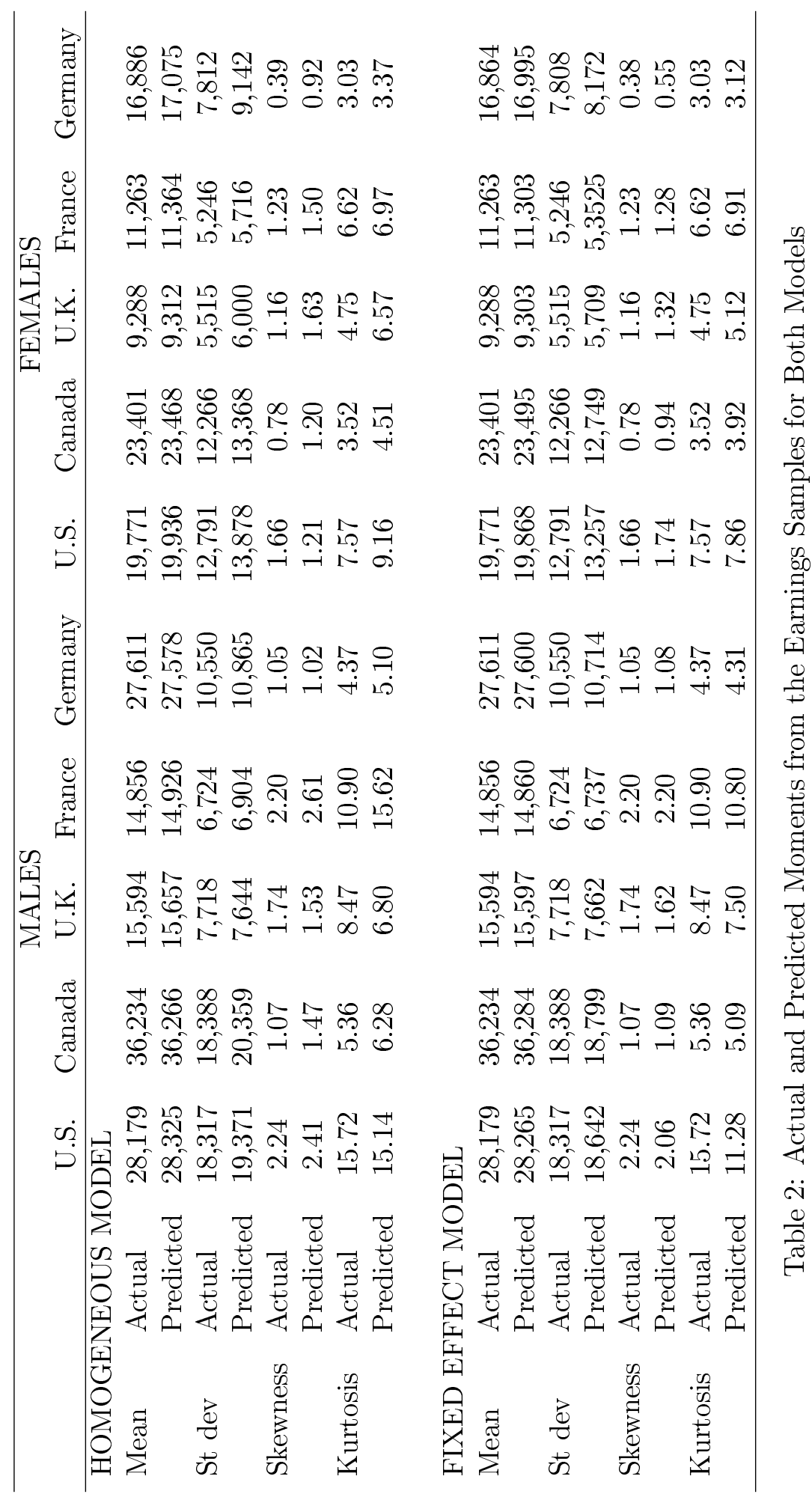




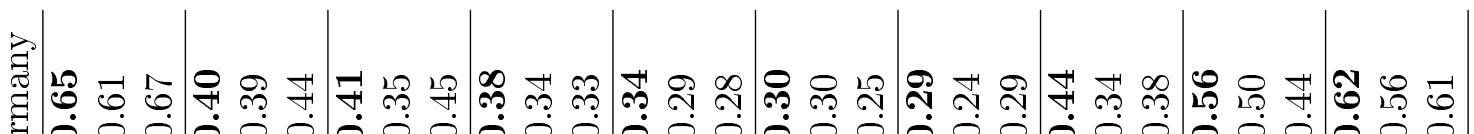
نे

氙

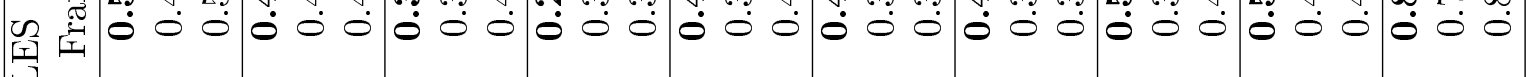

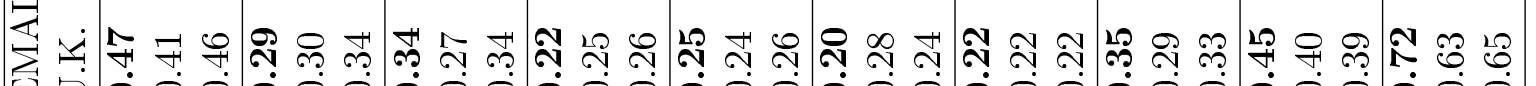

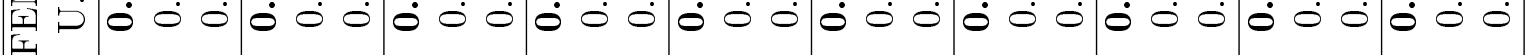
ఫ్త్ర శ్ ஸ்

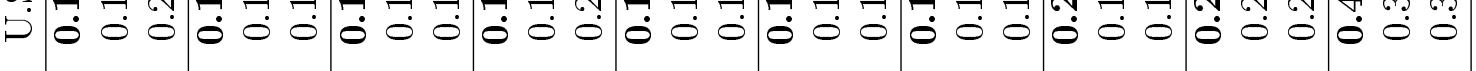
สี่

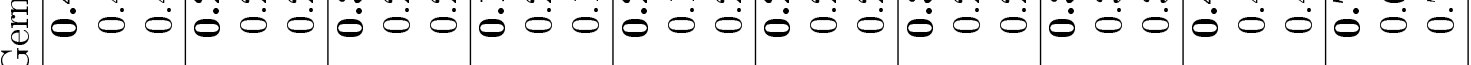

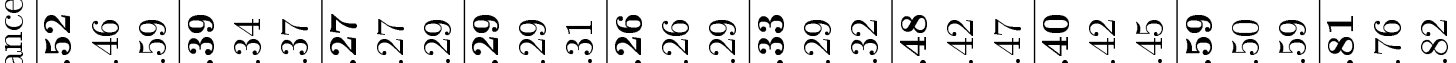
跑

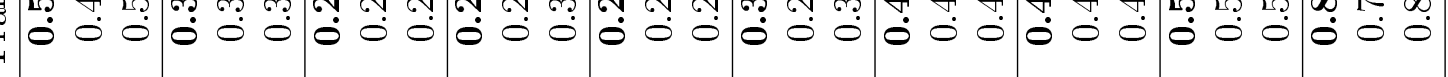

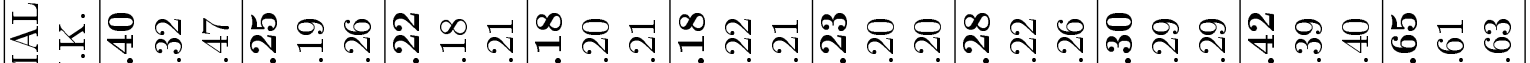

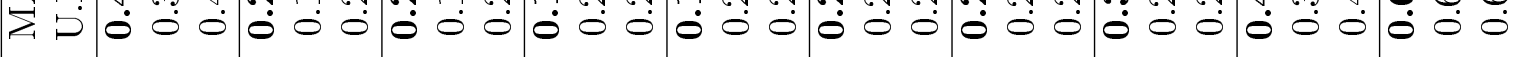

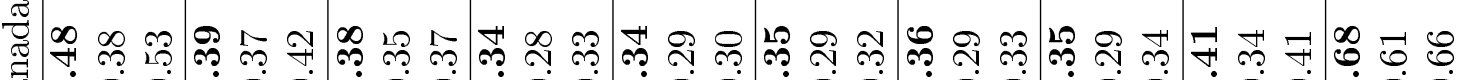
䒕

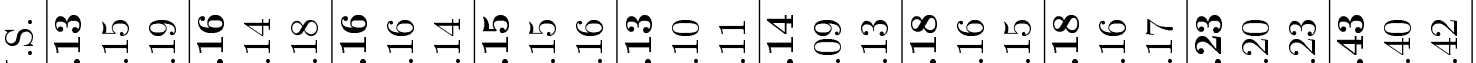

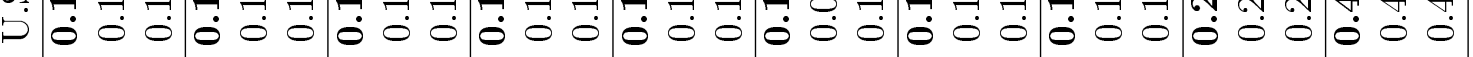

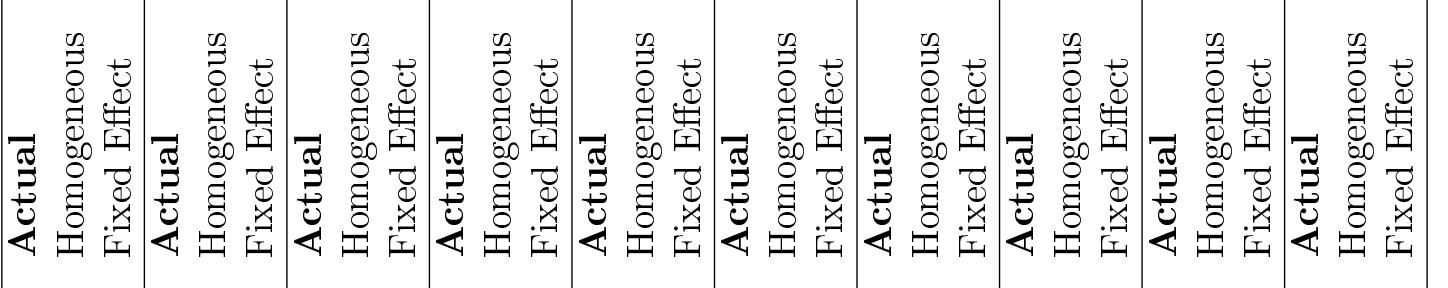




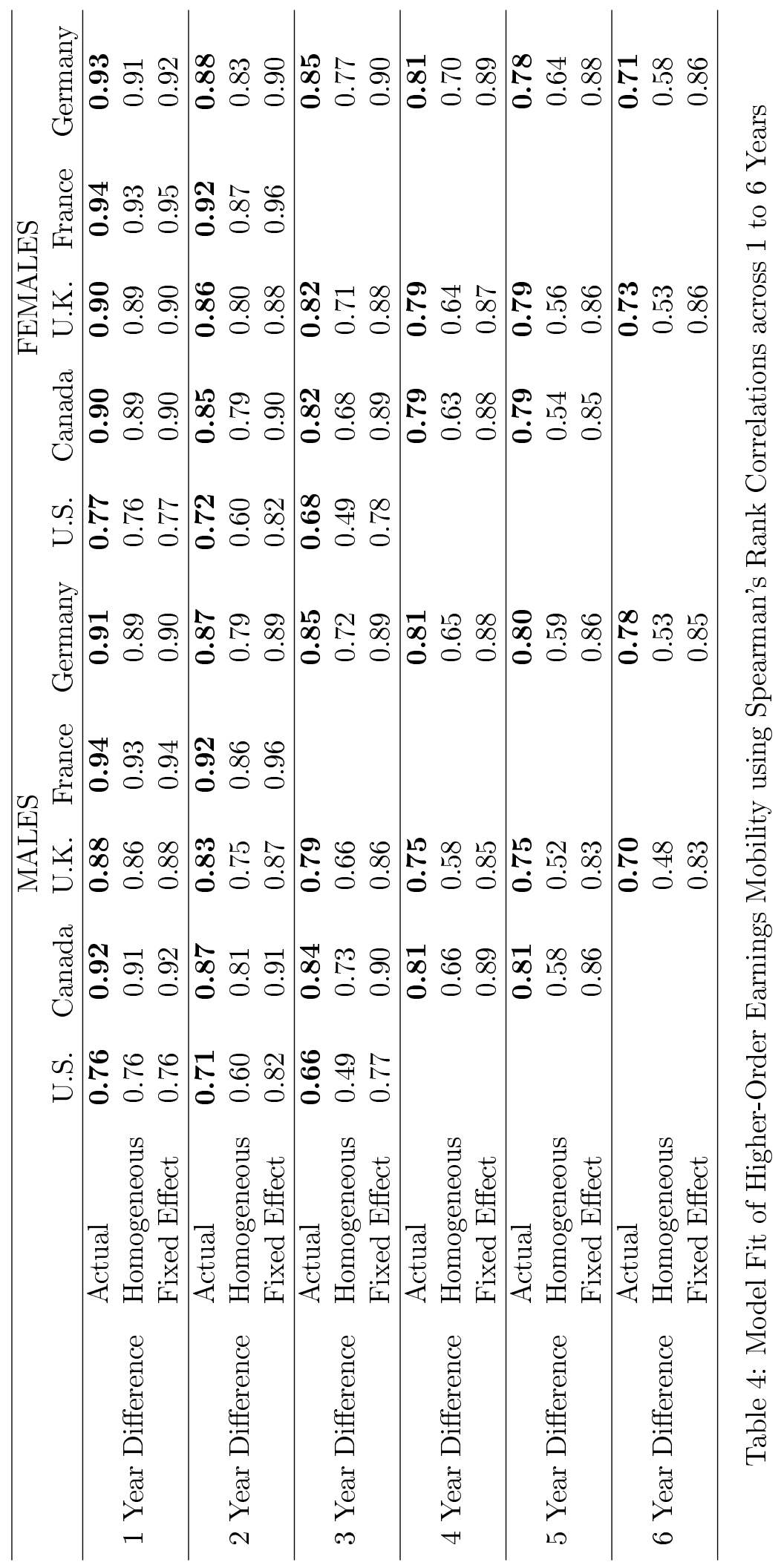




\begin{tabular}{llccccc}
\hline & & U.S. & Canada & U.K. & France & Germany \\
\hline MALES and FEMALES & & & & & \\
Gender Ratio & Current Earnings & 0.70 & 0.65 & 0.59 & 0.76 & 0.61 \\
& Ex-post Annuities, Hom. & 0.68 & 0.65 & 0.58 & 0.76 & 0.60 \\
& Ex-post Annuities, FE & 0.75 & 0.71 & 0.59 & 0.76 & 0.63 \\
MALES & & & & & \\
Education Ratio & Current Earnings & 2.51 & 1.74 & 1.70 & 2.04 & 1.88 \\
& Ex-post Annuities, Hom. & 2.59 & 1.74 & 1.79 & 2.30 & 2.37 \\
& Ex-post Annuities, FE & 2.65 & 1.73 & 1.70 & 2.27 & 2.11 \\
& & & & & & \\
Experience Ratio & Current Earnings & 1.27 & 1.29 & 1.06 & 1.14 & 1.32 \\
& Ex-post Annuities, Hom. & 1.04 & 1.01 & 0.89 & 0.97 & 1.02 \\
& Ex-post Annuities, FE & 0.98 & 0.98 & 0.90 & 1.00 & 1.05 \\
& & & & & & \\
FEMALES & & & & & & \\
Education Ratio & Current Earnings & 2.73 & 2.19 & 2.07 & 2.06 & 1.67 \\
& Ex-post Annuities, Hom. & 2.86 & 2.26 & 2.14 & 2.53 & 1.94 \\
& Ex-post Annuities, FE & 2.72 & 2.41 & 2.12 & 2.19 & 1.75 \\
& & & & & & \\
Experience Ratio & Current Earnings & 1.08 & 1.11 & 0.81 & 1.02 & 0.94 \\
& Ex-post Annuities, Hom. & 0.92 & 0.88 & 0.70 & 0.91 & 0.87 \\
& Ex-post Annuities, FE & 0.89 & 0.84 & 0.67 & 0.93 & 0.85 \\
\hline
\end{tabular}

Table 5: Ratios of Average Earnings and Lifetime Annuity Values for Employed Workers in 1998 


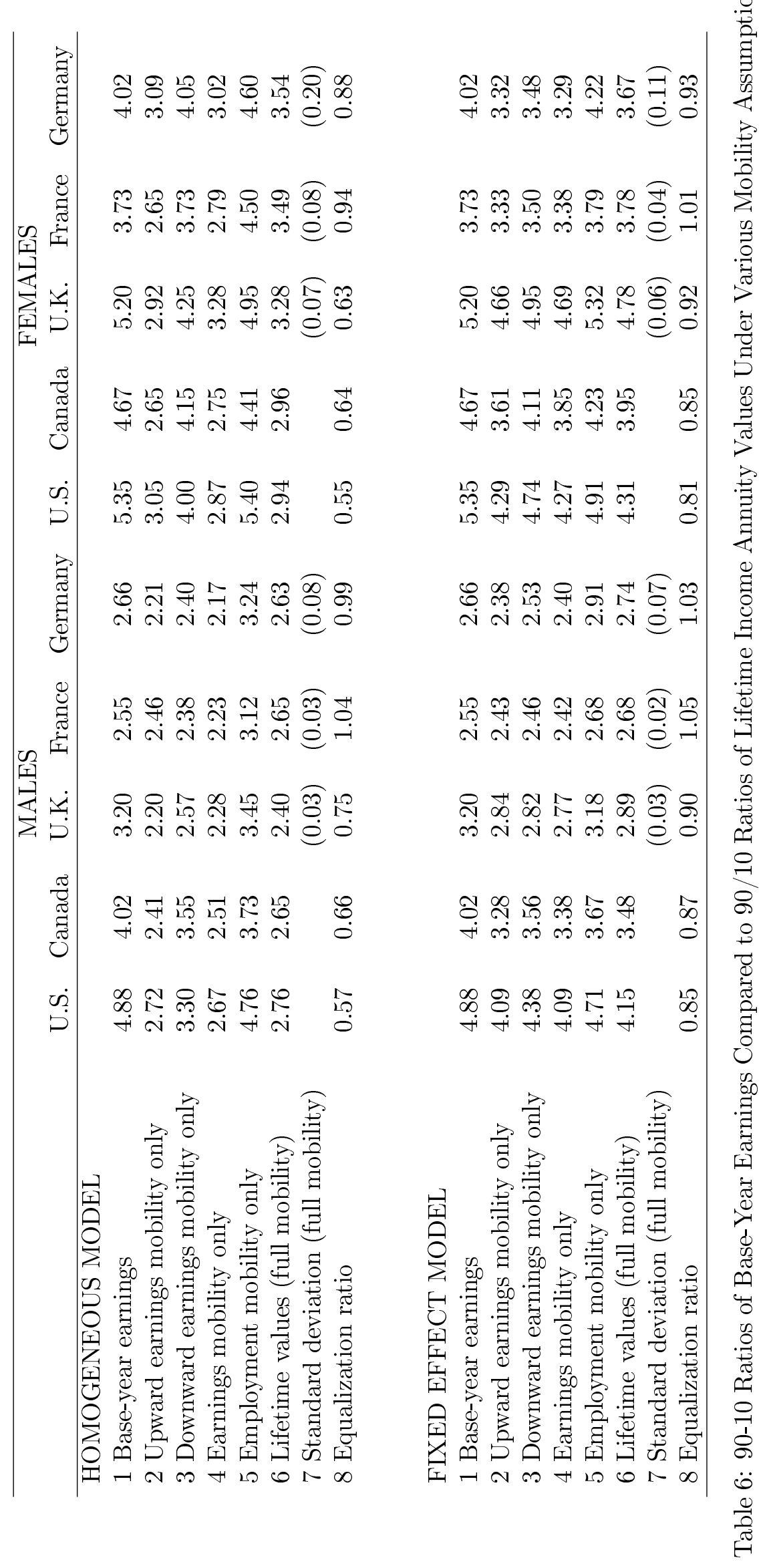




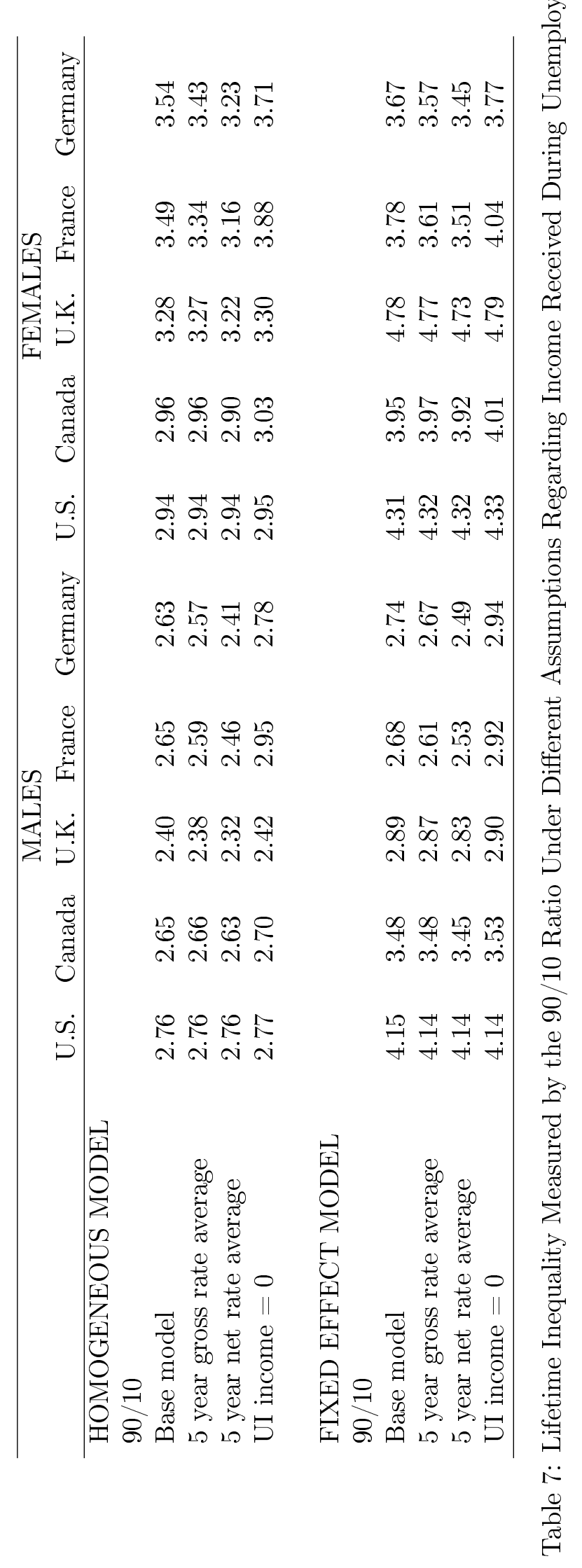




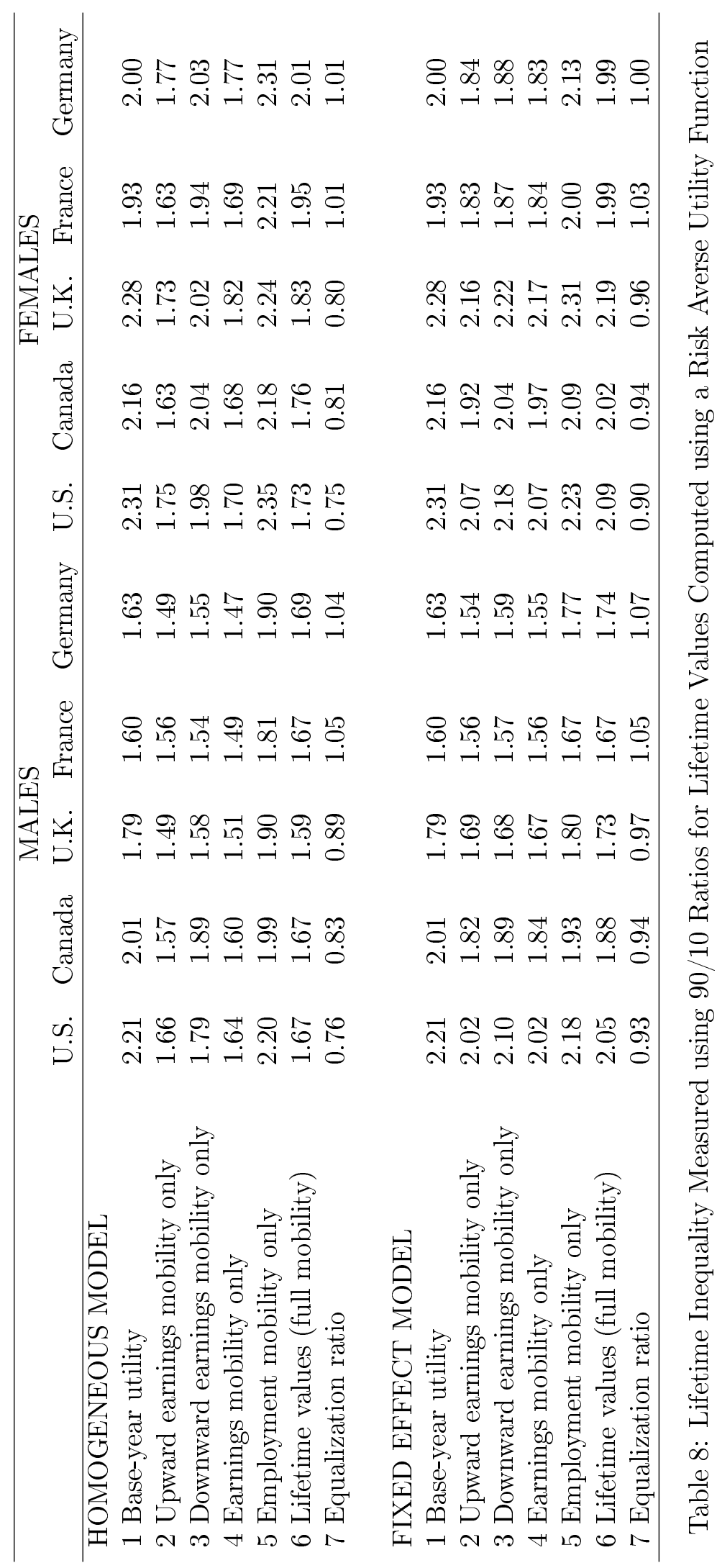

